\title{
Design, Fabrication and Performance Analysis of Loopwing Horizontal Axis Wind Turbine
}

\author{
Aye Aye Aung ${ }^{1}$, Myat Myat Soe ${ }^{2}$, War War Min $\mathrm{Swe}^{3}$ and Aung Myat Thu ${ }^{4}$ \\ Research Scholar ${ }^{1}$ and Professor ${ }^{2-4}$ and Associate Professor ${ }^{3}$ \\ ${ }^{1-4}$ Department of Mechanical Engineering \\ Mandalay Technological University \\ Patheingyi, Mandalay
}

Myanmar

\begin{abstract}
This research presents the design, fabrication and performance analysis of loopwing horizontal axis wind turbine. Among the many types of wind turbine, most of them failed in efficiency because of the higher rotating speed required in other conventional horizontal axis wind turbine. Another vertical axis wind turbine suffers unbalance torque between the right and left side which causes vibration. Loopwing horizontal axis wind turbine is operated at low rotating speed without reducing energy efficiency. There is no vortex discharge and noise because loopwing horizontal axis wind turbine has strip ribbons as its blade tip portion ends in a loop shape. Loopwing horizontal axis wind turbine blade is designed by the using of basic design formula such as angular momentum theory, blade element theory. The NASA SC(2)-0402 is chosen as the loopwing horizontal axis wind turbine blade profile by comparing it with a similar airfoil shape from the results of Profili Software. The model of loopwing horizontal axis wind turbine is drawn by using Solidworks 2018. Performance testing is carried out on the roof of Main-Building at Mandalay Technological University. The wind turbine hub is placed $14.6 \mathrm{~m}$ above the ground. The material of loop type blade wind turbine is stainless steel. The performance analysis of loopwing horizontal axis wind turbine is emphasized in this research. This loop type blade wind turbine can be started wind speed at $1.5 \mathrm{~m} / \mathrm{s}$ and cut-out wind speed at $12 \mathrm{~m} / \mathrm{s}$. Electrical power output can be produced by about $100 \mathrm{~W}$ by the following horizontal axis wind generator at rated wind speed $6 \mathrm{~m} / \mathrm{s}$. Rotor diameter is $1.5 \mathrm{~m}$ and the no. of the blade is three and the tip speed ratio is 5 .
\end{abstract}

Keywords: Loop Type Blade, Electrical Power, Torque Characteristics, Power Coefficient.

\section{INTRODUCTION}

There are some researcher who recently studies focus on the global awareness of climate changes, high energy prices and energy saving factors. Renewable energy is a term that has drawn the attention of scientists, engineers and even politicians toward itself during last five decades. The main idea behind renewable energy is to take advantage of the available natural energy resources, such as sun, wind, tides and many more, and convert them to the desired form of energy such as electricity. The generation of the electricity from renewable energy resources while minimizing any possible environmental effects is a positive alternative to mitigate the currently extraordinary use of fossil fuels. Therefore, many researcher has been tried to overcome these problem by using loopwing horizontal axis wind turbine technology. The purpose of this research not only to provide the electricity production in rual areas of Myanmar and but also will benefit the students from this loop type blade wind energy system. The main goal of loopwing horizontal axis wind turbine development is to increase the power output of the turbine. According to the Betz limit, wind power coefficient is a limited parameter for the conventional wind turbines. This loop type blade wind turbine is a core parameter to achieve the venturi effect and to increase energy efficiency with low noisy level and also activate generation with low rotating speed. The importance of renewable energy based loopwing wind turbine for generating electricity. There are many researchers have been efforts to generate electricity from wind energy in which optimum design of blade profile is the most important procedure to enhance the efficiency of the wind turbine. The geometry of loopwing horizontal axis wind turbine with attached to the tower is drawn by Solidwork 2018 as shown in Figure 1.1 [1]. 


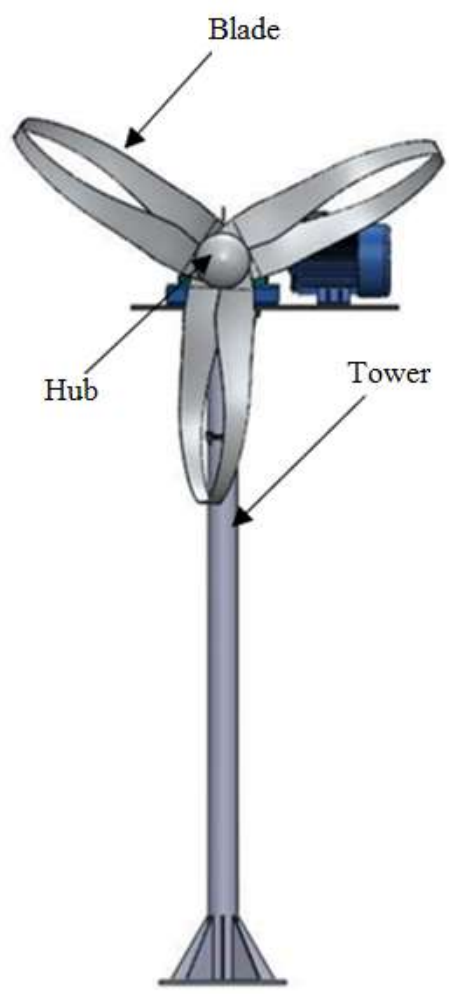

Figure1.1: 3D Model of Loopwing Horizontal Axis Wind Turbine

\section{DESIGN PARAMETERS IN LOOPWING HORIZONTAL AXIS WIND TURBINE}

The venturi effect is utilized in a new type of loopwing horizontal axis wind turbine design to create a turbine with lower relative noise and energy generation at lower wind speed conditions. The efficiency of wind turbine and velocity can be increased by the venturi effect. In this proposed, the aerodynamics analysis of loopwing horizontal axis wind turbine is studied emphasis such as the angular momentum theory, blade element theory, basic design formula. Basic design formulas is also included in terms of tip speed ratio, twist angle and chord length of loop type blade wind turbine.

\subsection{Sizing of Loopwing Wind Turbine Rotor}

The portion of the wind turbine that collects energy from the wind is called the rotor. The blades are attached to the hub, which in turn is attached to the main shaft. The rotor swept area can be computed by the following equation.

$$
A=\frac{P}{C_{p} \frac{1}{2} \rho V^{3} \eta_{O}}-----(1)
$$

\subsection{Chord Length}

Blade width is determine by a chord length and variation of the chord length with respect to the inflow angle.

$$
\mathrm{C}=\frac{8 \pi \mathrm{R}(1-\cos \varphi)}{\mathrm{Bc}_{1}}-------(2)
$$

\subsection{Inflow Angle and Twist Angle}

Twist angle and installation angle of airfoil is an essential parameter to design blade profile. It can be called inflow angle that designates an angle between the direction of relative wind and rotation plane of blade. The angle of attack is an angle between the direction of relative wind and chord line. Variable angle of blade profile are;

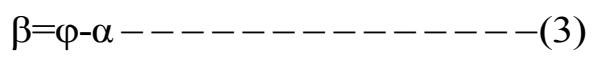


International Journal of Advances in Scientific Research and Engineering (ijasre), Vol 5 (12), December-2019

$$
\begin{array}{r}
\varphi=\tan ^{-1}\left[\frac{2}{3} \times \frac{1}{\lambda_{\mathrm{r}}}\right]--------(4) \\
\lambda_{\mathrm{r}}=\lambda \times \frac{\mathrm{r}}{\mathrm{R}}------------(5)
\end{array}
$$

\subsection{Blade Element Theory}

The component of force perpendicular to the direction of the undisturbed flow is called the lift force $\mathrm{dF}_{\mathrm{L}}$. The force in the direction of the undisturbed flow is called the drag force $\mathrm{dF}_{\mathrm{D}}$. It can be seen that the thrust $\mathrm{dF}_{\mathrm{T}}$ and torque $\mathrm{dT}$ acting on the blade element are

$$
\begin{aligned}
& \mathrm{dF}_{\mathrm{L}}=\frac{1}{2} \rho \mathrm{AV}_{\mathrm{r}}^{2} \mathrm{C}_{\mathrm{L}}----------(6) \\
& \mathrm{dF}_{\mathrm{D}}=\frac{1}{2} \rho \mathrm{AV}_{\mathrm{r}}^{2} \mathrm{C}_{\mathrm{D}}-----------(7) \\
& \mathrm{dF}_{\mathrm{T}}=\frac{1}{2} \rho \mathrm{AV}_{\mathrm{r}}^{2}\left(\mathrm{C}_{\mathrm{L}} \sin \varphi-\mathrm{C}_{\mathrm{D}} \cos \varphi\right)-----(8) \\
& \mathrm{dT}=\mathrm{r}_{1}\left(\mathrm{dL}_{1} \sin \varphi_{1}-\mathrm{dD}_{1} \cos \varphi_{1}\right)-------(9) \\
& \mathrm{dP}=\omega \mathrm{T}---------------(10) \\
& \mathrm{P}_{\mathrm{e}}=\mathrm{P}_{\mathrm{T}} \eta_{\mathrm{g}} \eta_{\mathrm{m}}-------------(11)
\end{aligned}
$$

Table 1.1. Forces and Power for Each Blade Section of NASA SC(2)-0402

\begin{tabular}{|c|c|c|c|c|c|}
\hline Sections & $\begin{array}{c}\mathbf{d F}_{\mathbf{L}} \\
(\mathbf{N})\end{array}$ & $\begin{array}{c}\mathbf{d F}_{\mathbf{D}} \\
(\mathbf{N})\end{array}$ & $\begin{array}{c}\mathbf{d F}_{\mathbf{T}} \\
(\mathbf{N})\end{array}$ & $\begin{array}{c}\mathbf{d T} \\
(\mathbf{N})\end{array}$ & $\begin{array}{c}\mathbf{d P} \\
(\mathbf{W})\end{array}$ \\
\hline $\mathbf{1}$ & 0.104 & 0.006 & 0.081 & 0.005 & 0.196 \\
\hline $\mathbf{2}$ & 0.223 & 0.014 & 0.200 & 0.016 & 0.626 \\
\hline $\mathbf{3}$ & 0.347 & 0.022 & 0.330 & 0.028 & 1.116 \\
\hline $\mathbf{4}$ & 0.472 & 0.031 & 0.459 & 0.041 & 1.612 \\
\hline $\mathbf{5}$ & 0.597 & 0.039 & 0.588 & 0.054 & 2.101 \\
\hline $\mathbf{6}$ & 0.722 & 0.047 & 0.715 & 0.066 & 2.584 \\
\hline $\mathbf{7}$ & 0.846 & 0.055 & 0.841 & 0.079 & 3.061 \\
\hline $\mathbf{8}$ & 0.969 & 0.063 & 0.967 & 0.091 & 3.535 \\
\hline $\mathbf{9}$ & 1.093 & 0.071 & 1.091 & 0.103 & 4.893 \\
\hline $\mathbf{1 0}$ & 1.229 & 0.080 & 1.291 & 0.117 & 4.520 \\
\hline
\end{tabular}

The power output of each elements for NASA SC(2)-0402 is shown in Table1.1. The power output is directly varied according to the blade length. The power on the blade length is gradually increased from root to tip. Therefore, the tip section twist angle is important to produce more power. The entire blade of wind turbine power output is the summation of each section.

\subsection{Shaft Design}

Shaft is a rotating machine element used to transfer power from one point to the other. The power of shaft can be obtained by the resultant torque. The shaft that has been used the solid shaft for this design condition. The cast iron material, that is used in solid shaft is cut by the gas welding process. The hub is a part that is fixed with the rotating shaft and the blade flange. The torsional moment $\left(\mathrm{M}_{\mathrm{t}}\right)$ on the shaft can be calculated by using the following equation. Design parameter for loopwing horizontal axis wind turbine is shown in Table1.2. 
International Journal of Advances in Scientific Research and Engineering (ijasre), Vol 5 (12), December-2019

$$
\mathrm{M}_{\mathrm{t}}=\frac{60 \mathrm{P}}{2 \pi \mathrm{N}}
$$

Bending moment $\left(\mathrm{M}_{\mathrm{b}}\right)$ on the shaft can be calculated from the overall weight acting on the shaft.

$$
\mathrm{M}_{\mathrm{b}}=\mathrm{W} \times \mathrm{L}
$$

The equilvalent twisting moment of the shaft can be calculated

$$
\mathrm{T}_{\mathrm{e}}=\frac{\pi}{16} \tau \mathrm{d}^{3}
$$

For without considering the axial compression load, the equilvalent twisting moment of the shaft can be calculated by using following Equation.

$$
\mathrm{T}_{\mathrm{e}}=\sqrt{\left(\mathrm{k}_{\mathrm{b}} \mathrm{M}_{\mathrm{b}}\right)^{2}+\left(\mathrm{k}_{\mathrm{t}} \mathrm{M}_{\mathrm{t}}\right)^{2}}
$$

Table1.2. Design Parameter for Loopwing Wind Turbine

\begin{tabular}{|c|c|c|c|c|}
\hline No. & Parameter & Symbol & Value & Unit \\
\hline $\mathbf{1 .}$ & Diameter of rotor & $\mathrm{D}$ & 1.594 & $\mathrm{~m}$ \\
\hline $\mathbf{2 .}$ & No.of blade & $\mathrm{n}$ & 3 & Nos \\
\hline $\mathbf{3 .}$ & Chord length of airfoil & $\mathrm{C}$ & 0.202 & $\mathrm{~m}$ \\
\hline $\mathbf{4 .}$ & Airfoil thickness & $\mathrm{t}$ & 0.002 & $\mathrm{~m}$ \\
\hline $\mathbf{5 .}$ & Total lift force & $\mathrm{F}_{\mathrm{L}}$ & 39.6 & $\mathrm{~N}$ \\
\hline $\mathbf{6 .}$ & Total drag force & $\mathrm{F}_{\mathrm{D}}$ & 2.604 & $\mathrm{~N}$ \\
\hline $\mathbf{7 .}$ & Total thrust force & $\mathrm{F}_{\mathrm{Ts}}$ & 39.036 & $\mathrm{~N}$ \\
\hline $\mathbf{8 .}$ & Torque & $\mathrm{T}$ & 3.63 & $\mathrm{Nm}$ \\
\hline $\mathbf{9 .}$ & Shaft Diameter & $\mathrm{d}$ & 32 & $\mathrm{~mm}$ \\
\hline
\end{tabular}

\section{DESIGN DRAWING OF LOOPWING HORIZONTAL AXIS WIND TURBINE}

The propose design rotor has three stainless steel blades and six flange for three blades. This turbine assembly consists of three main parts as blade, tower and generator. Geometry for detail dimension of loopwing horizontal axis wind turbine front view, side view and isometric view are shown in Figrue 3.1 and 3.2.

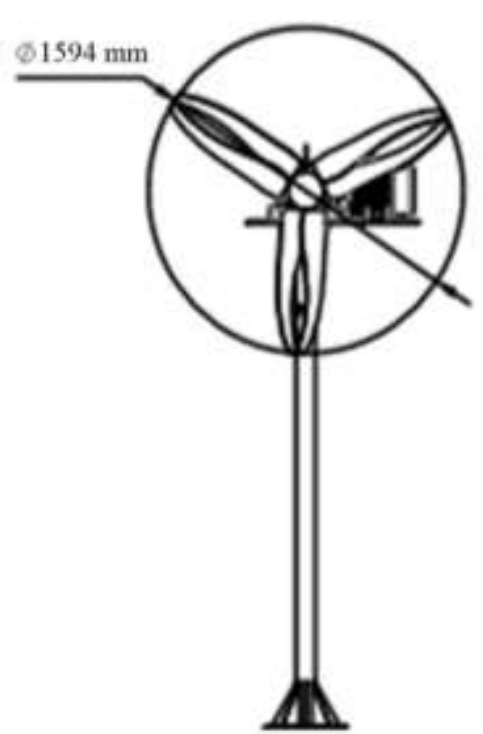

(a) Front View of LWHAWT

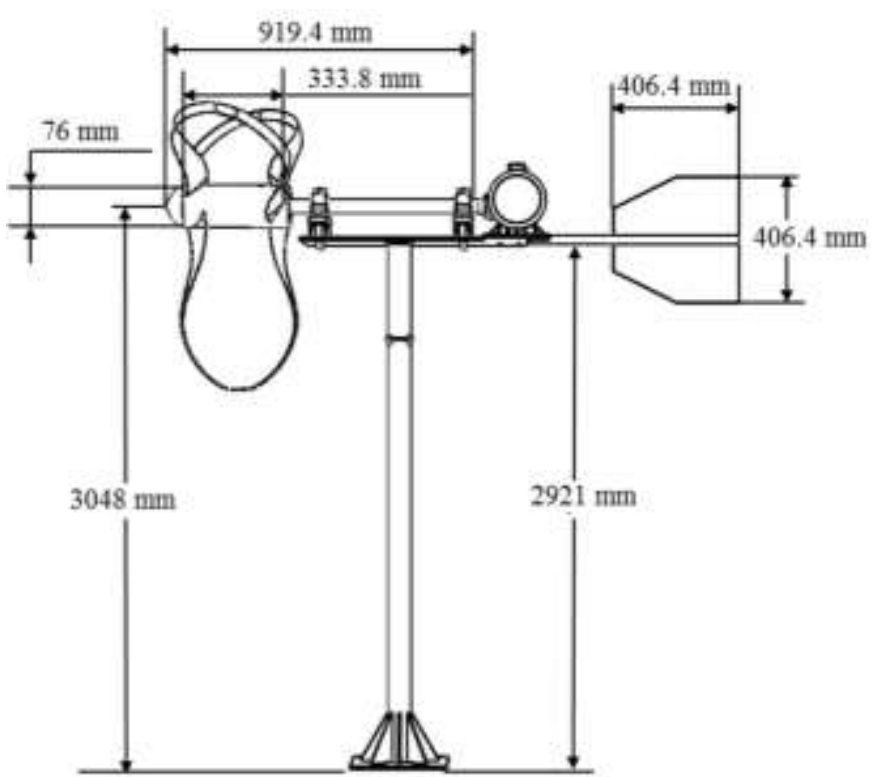

(b) Side View of LWHAWT

Figure 3.1: Front and Side View of Loopwing Horizontal Axis Wind Turbine 


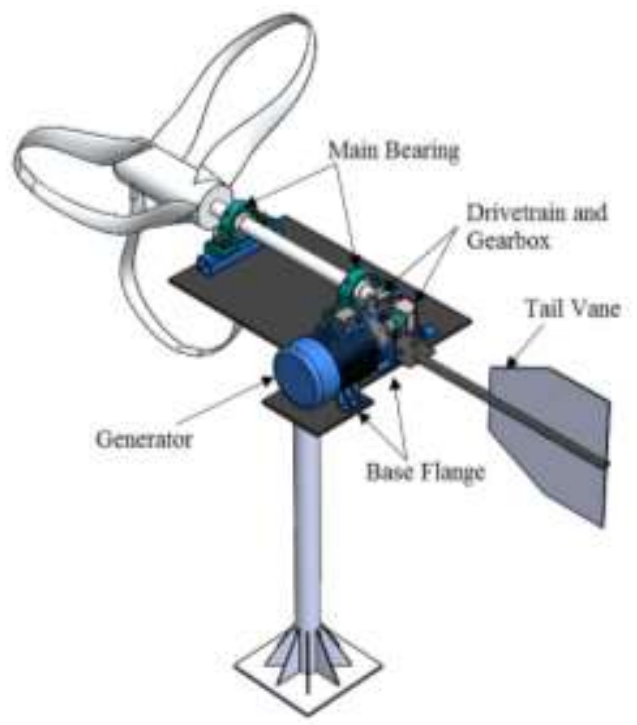

Figure 3.2: Isometric View for Complete Assembly of Loopwing Horizontal Axis Wind Turbine

In this research, includes the fabrication of turbine assembly. Blades are one of the main components of the wind turbine and extreme care was taken to choose the materials for the intended application. Stainless steel material can be maintained easily and simply in a high quality, pleasing for loop shape blade wind turbine. Loopwing horizontal axis wind turbine blade can be cut on the steel sheet by using hand grinder. Right and left side layer of the blade were pressed by using hydraulic machine to control the causes of blade vibration.

\subsection{Performance Analysis of Loopwing Horizontal Axis Wind Turbine}

Loopwing rotor assembly is attached to the tower which is located on the roof of the main building slab at Mandalay Technological University. Figure 3.3 is expressed the rotor, hub and shaft of loopwing horizontal axis wind turbine.

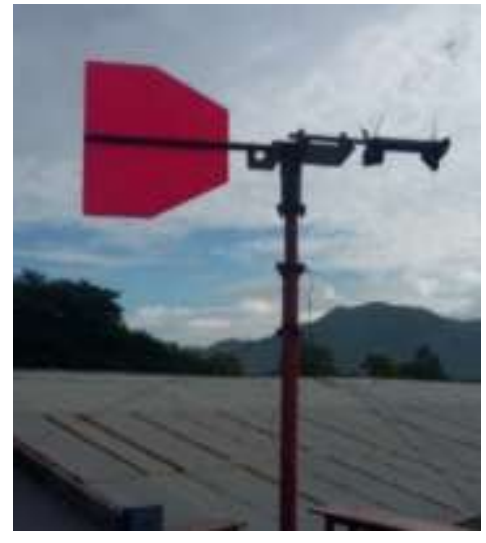

(a) Assembly of Hub, Shaft, Tail Vane

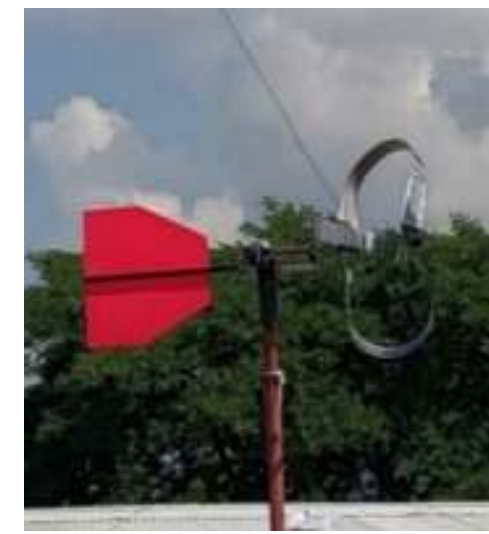

(b) Assembly of LWHAWT

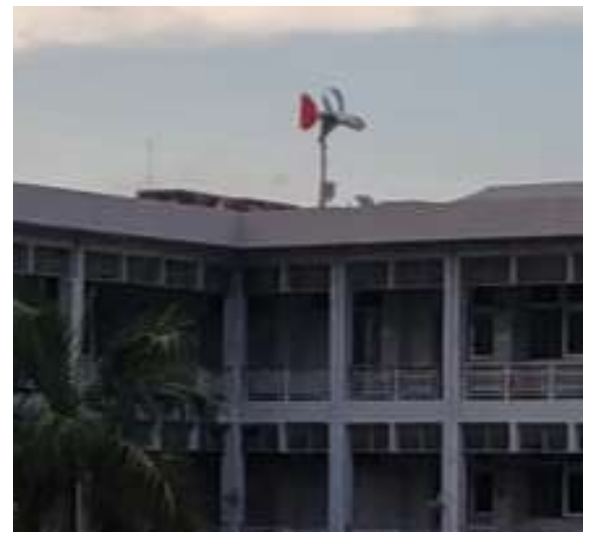

(c) Assembly of LWHAWT at MTU

Figure 3.3: Loopwing Horizontal Axis Wind Turbine on the Roof of Main Building Slab at MTU

In the performance test, it mainly described the site apparatus and measuring instruments for the test. Wind speed is collected with hand-held anemometer and the wind direction is traced harmonically with the rotor facing direction by manually. The output current is measured by clamp meter. Clamp meters can be capabled of measuring both ac and dc current. Determining how much current have been flowing in various branch circuits is a fairly common task for the electrician. Another common function for a clamp meter is to measure voltage. Typical current measurements are taken on various branch circuits of an electrical distribution system and the turbine rotational speed is measured by digital display tachometer. Tachometer has been utilized to measure the revolution per minute (RPM) of the proposed loopwing horizontal axis wind turbine. The number of rotation is precisely counted by the tachometer from rotating shaft. 
The daily maximum average wind speed is collected at in October. The bar chart of wind speed data are shown in Figure 3.4. It is observed that wind speed is slightly increased about 3.5 to $7.9 \mathrm{~m} / \mathrm{s}$ from $12^{\text {th }}$ Oct to $16^{\text {th }}$ Oct. It is found that the lowest wind speed condition is in $23^{\text {th }}$ Oct that is due to the low intensity wind speed and high surrounding temperature. According to the experiment test result, monthly average wind speed is obtained about $3.852 \mathrm{~m} / \mathrm{s}$.

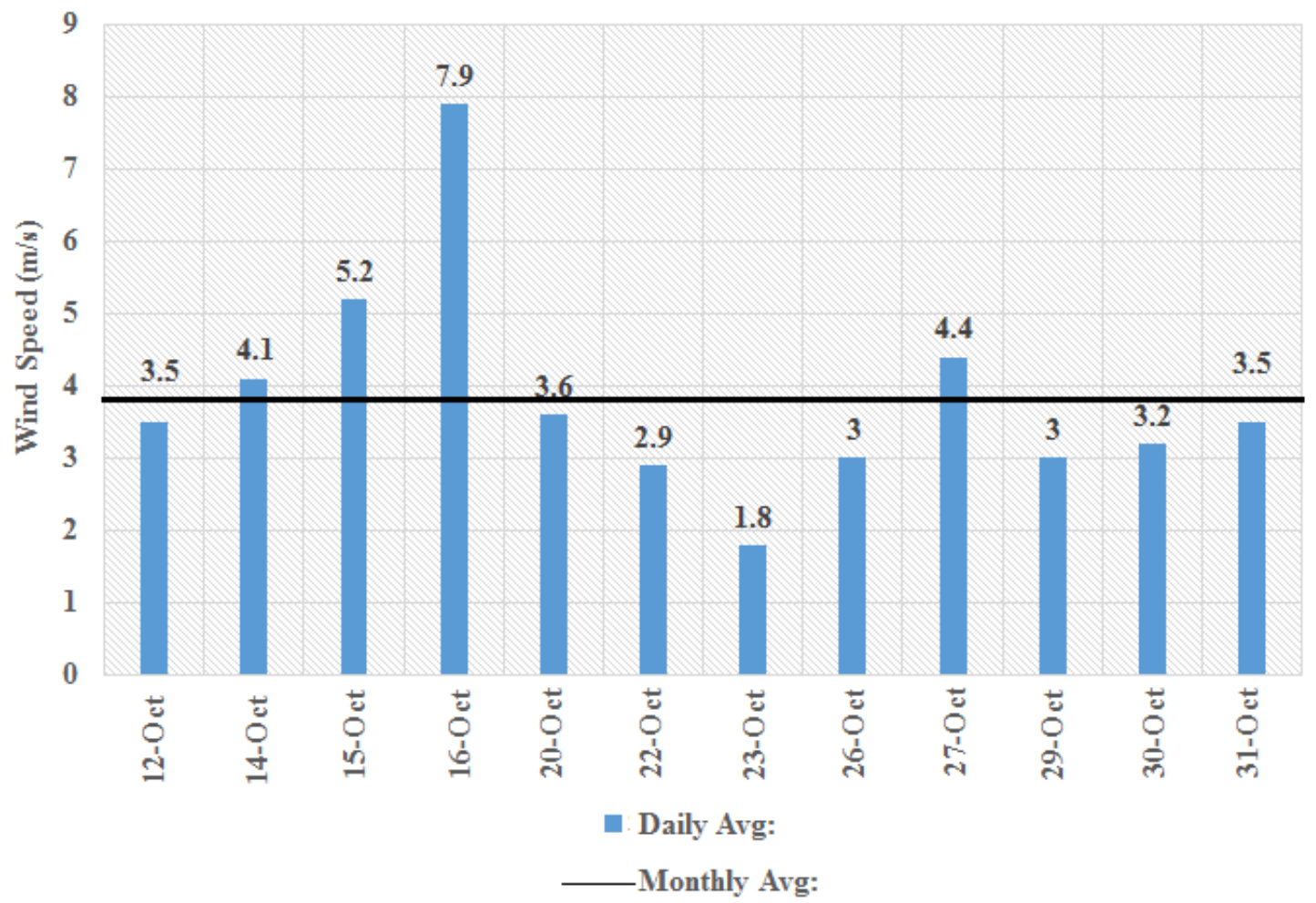

Figure 3.4: Average Wind Speed for October 2019 at MTU

Performance test result of electrical power output curve are shown in Figure 3.5. It is found that the electrical power output trend is slightly increased during the $12^{\text {th }}$ Oct to $16^{\text {th }}$ Oct. In $16^{\text {th }}$ Oct electrical power trend is produced higher than any other day of October. Wind speed is low in summer and high in monsoon place. It is monsoon day of the month during the day of October.

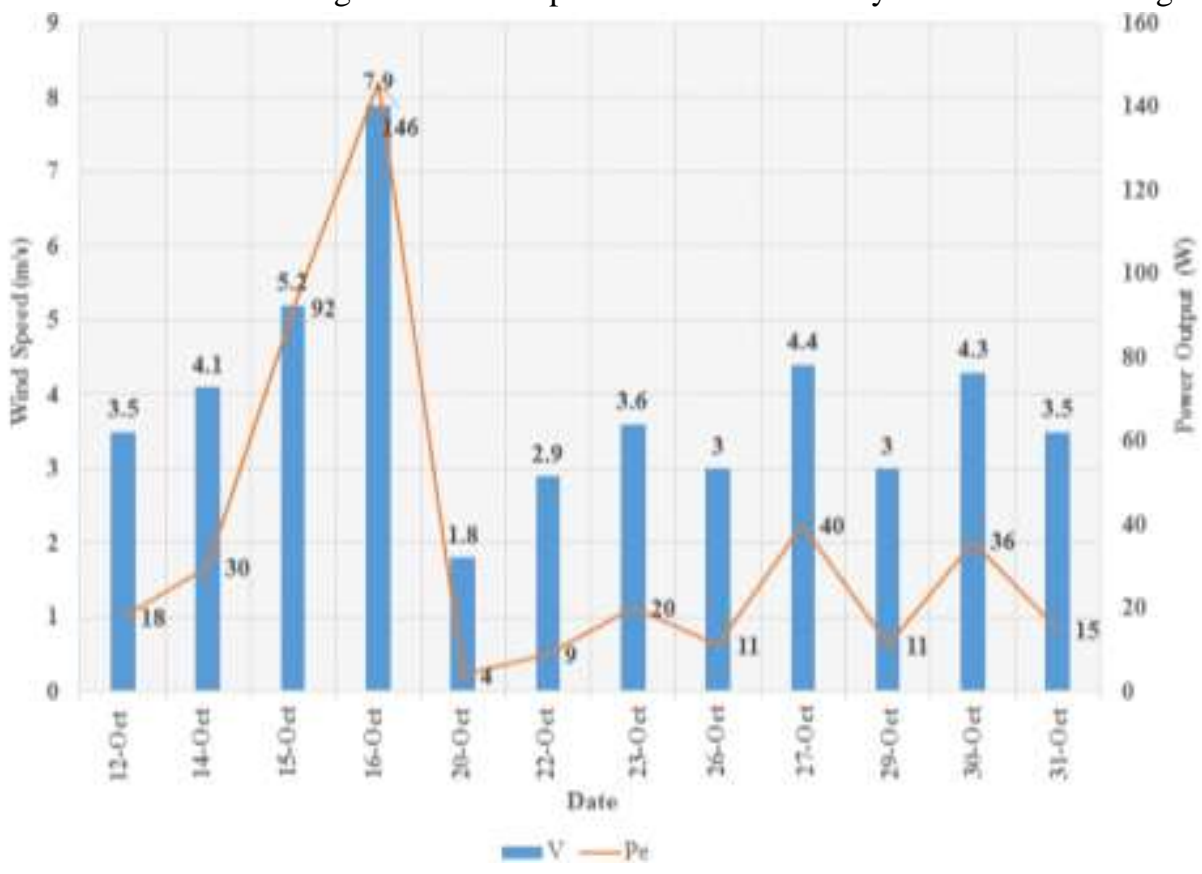

Figure 3.5: Electrical Power Output at Various Wind Speed Condition

Electrical power output is depended on the wind speed condition. Therefore, wind turbine electrical power output may be changed in the various wind speed condition. According to the performance test result, wind speed is around $1.8 \mathrm{~m} / \mathrm{s}$ to $7.9 \mathrm{~m} / \mathrm{s}$ thus the electrical power output is the range from $4 \mathrm{~W}$ to $146 \mathrm{~W}$ respectively. 


\subsection{Performance Test Results of Loopwing Horizontal Axis Wind Turbine}

During the testing, it was determined that the start speed for the turbine was about $1.5 \mathrm{~m} / \mathrm{s}$ and power was approximately produced about $1.8 \mathrm{~m} / \mathrm{s}$. Performance test result of voltage, current, electrical power output, torque, and power of coefficient for various wind speed condition are shown in Table 3.1 .

Table 3.1. Performance Test Results for Various Wind speed Condition

\begin{tabular}{|c|c|c|c|c|c|c|c|}
\hline $\begin{array}{l}\text { Test } \\
\text { Run }\end{array}$ & $\begin{array}{l}\text { Wind } \\
\text { Speed } \\
(\mathbf{m} / \mathbf{s})\end{array}$ & $\begin{array}{c}\text { Voltage } \\
\text { (V) }\end{array}$ & $\begin{array}{c}\text { Current } \\
\text { (A) }\end{array}$ & $\begin{array}{l}\mathbf{P e} \\
(\mathrm{W})\end{array}$ & $\begin{array}{c}\mathbf{N} \\
(\mathbf{r p m})\end{array}$ & $\begin{array}{c}T \\
(\mathbf{N m})\end{array}$ & $\mathbf{C}_{\mathrm{P}}$ \\
\hline 1 & 3 & 116.00 & 0.094 & 10.904 & 166.0 & 0.60 & 0.13 \\
\hline 2 & 6 & 119.24 & 0.907 & 108.403 & 351.8 & 3.25 & 0.38 \\
\hline 3 & 9 & 119.36 & 1.669 & 200.011 & 393.3 & 5.02 & 0.40 \\
\hline 4 & 12 & 129.10 & 3.205 & 368.288 & 450.0 & 10.27 & 0.43 \\
\hline
\end{tabular}

Experiment test results of loopwing horizontal axis wind turbine output voltage and current results are plotted at various design wind speed condition. Output voltage and current is measured the manual measuring system by using clamp meter. It can be seen that the output voltage and current is gradually increased at the various wind speed condition. Output voltage is the range from 116 to $130 \mathrm{~V}$ and current is from 0.09 to 3.2 A respectively. Performance test result of output voltage and current characteristic curve is expressed in Figure 3.6.

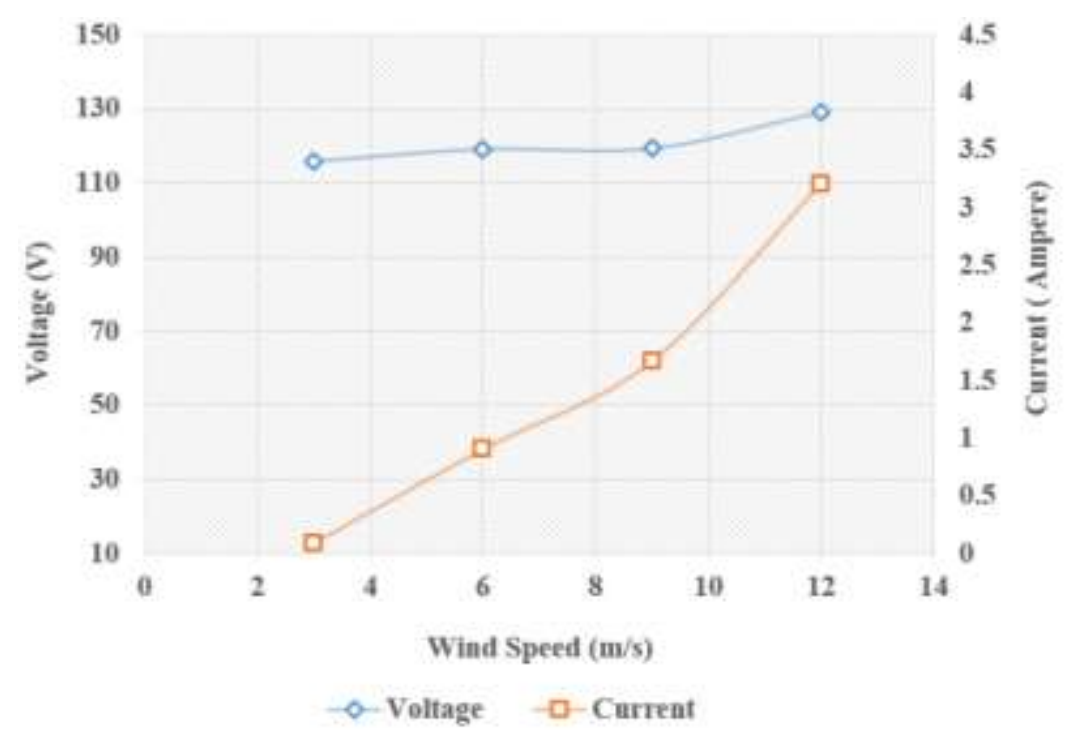

Figure 3.6: Performance Test Result of Voltage and Current at Various Wind Speed Condition

Performance of loopwing horizontal axis wind turbine was evaluated in terms of the relation between electrical power output and rotational speed at various wind speed conditons. Voltage and current is directly proportional to the wind speed condition. Voltage and current can be changed by the incoming wind speed condition. The characteristics curves of electrical power and rotational speed are shown in Figure 3.7. 


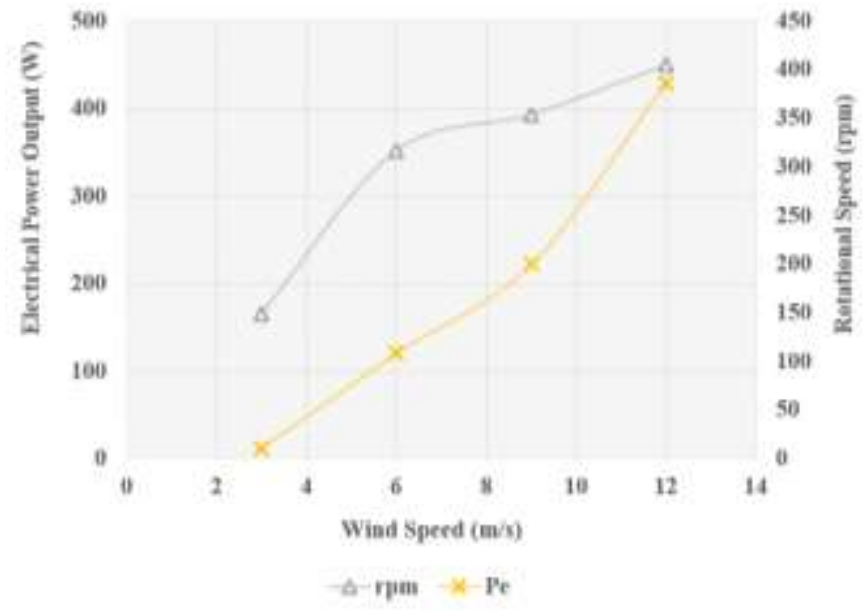

Figure 3.7: Performance Test Result of Electrical Power Output and Rotational Speed at Various Wind Speed Condition

Rotational speed is measured by using tachometer. It can be seen that the electrical power output and rotational speed is gradually increased at the various wind speed condition. Rotational speed is directly proportional to the wind speed condition. If the value of wind speed is high, the value of rotational speed is also high. Therefore, rotational speed is gradually increased from 166 to 450 rpm respectively. Electrical power output is the range from 10 to $400 \mathrm{~W}$ at various wind speed condition. Comparison of averge torque for theoretical result and performance test result at various wind speed conditions are shown in Figure 3.8.

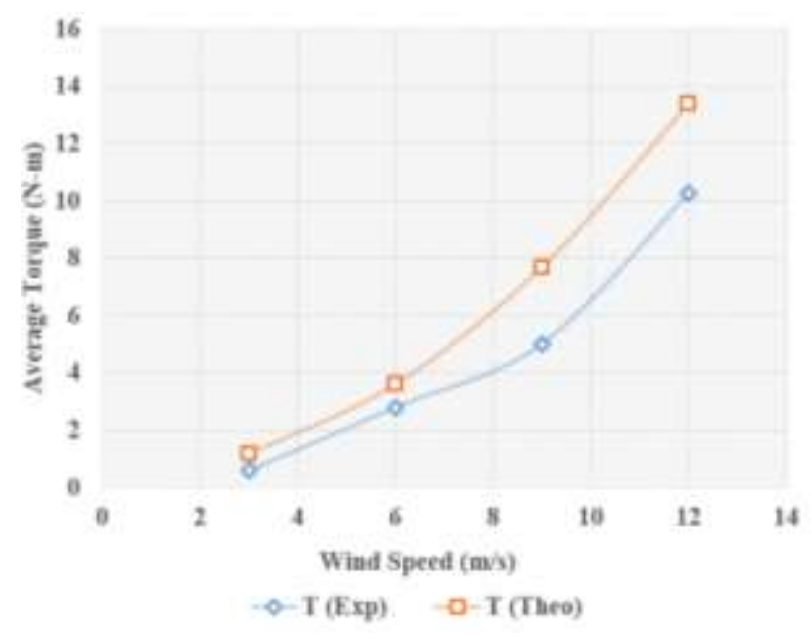

Figure 3.8: Experiment Test Result and Theoretical Result of Average Torque at Various Wind Speed Conditions

Average torque of performance test result is $3.25 \mathrm{Nm}$ and theoretical result is $3.63 \mathrm{Nm}$ at rated wind speed $6 \mathrm{~m} / \mathrm{s}$. It can be found that, a little deviation between theoretical and performance test result because of manual measuring system and the rotational speed of the shaft. Rotational speed is varied according to the wind speed condition. Wind speed is varies with the seasonal variation. Comparison of electrical power output for theoretical result and performance test result at various wind speed conditions are shown in Figure 3.9.

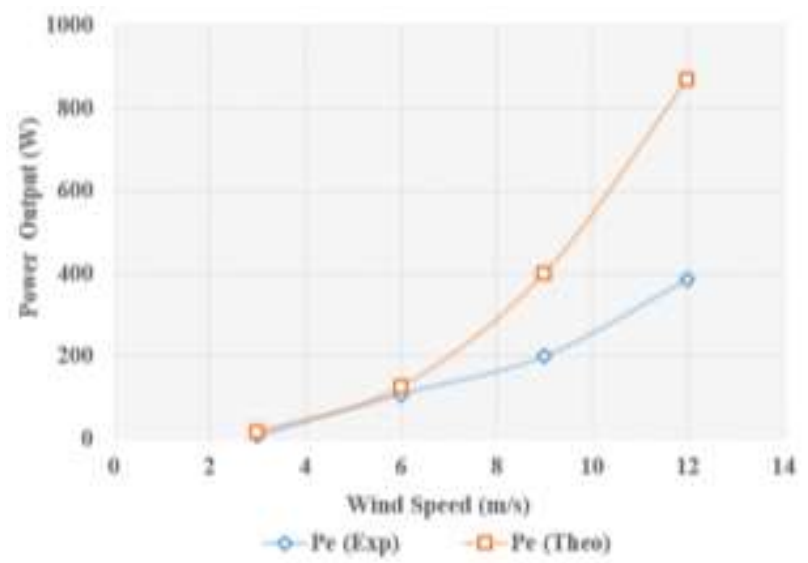

Figure 3.9: Experiment and Theoretical Result of Power Output at Various Wind Speed 
According to the experiment test result, electrical power output of experiment test result is $126 \mathrm{~W}$ and theoretical result is $108 \mathrm{~W}$ at design wind speed condition. If the more wind speed condition, the more power can be produced. Comparison of the power coefficient of theoretical result and performance test result at various wind speed conditions are shown in Figure 3.10.

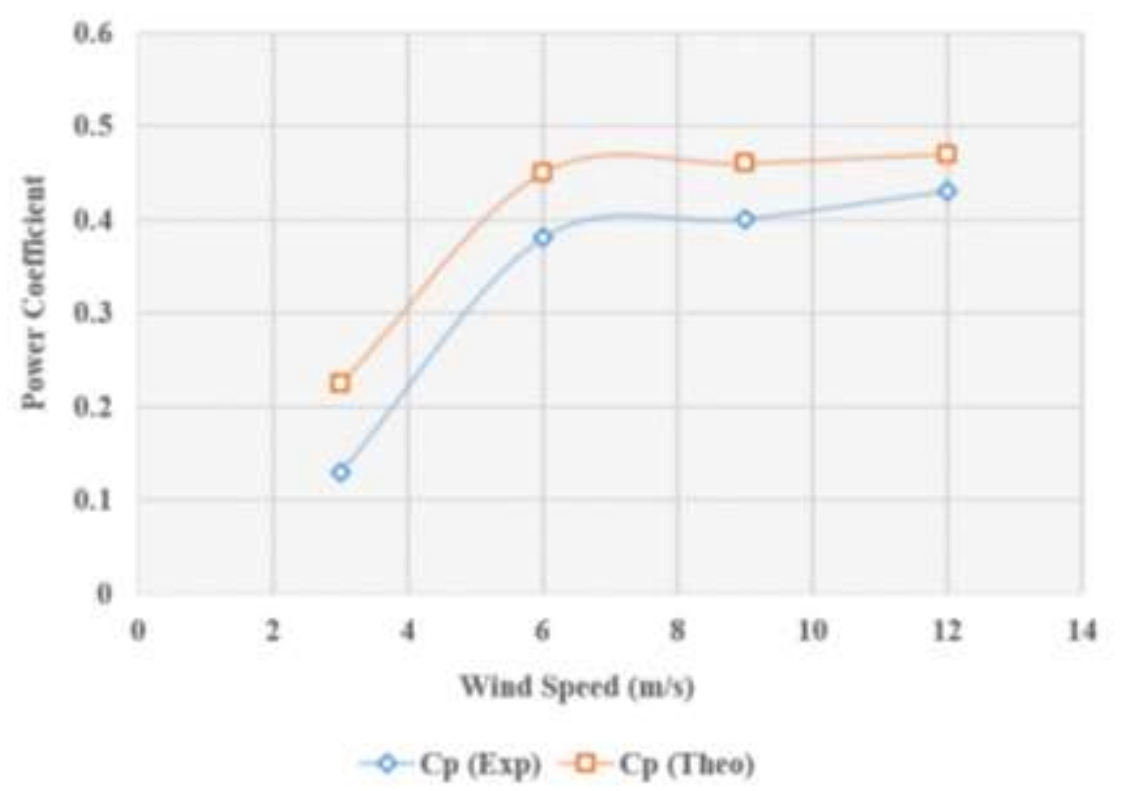

Figure 3.10: Experiment and Theoretical Result of Power of Coefficient at Various Wind Speed Conditions

Performance test result of power coefficient trend is gradually increased at various wind speed condition. By comparing the research experiment test and theoretical result, it is found that the power coefficient of a loopwing horizontal axis wind turbine meets a good agreement.

\section{RESULT AND DISCUSSION}

Every wind turbine design, wind speed condition is very important. The design power output can be changed by the loopwing horizontal axis wind turbine area and the incoming wind speed condition. The comparison of theoretical and experiment test result of torque, power output and power coefficient are described as shown in Table 4.1.

Table 4.1. Theoretical and Experiment Test Results Deviation at Rated Wind Speed 6 m/s

\begin{tabular}{|c|c|c|c|c|}
\hline No. & Name & Theo; & Exp; & Deviation \% \\
\hline 1. & Torque $(\mathrm{Nm})$ & 3.63 & 3.25 & $11 \%$ \\
\hline 2. & Power $(\mathrm{W})$ & 126.6 & 108.4 & $14 \%$ \\
\hline 3. & Power Coefficient & 0.45 & 0.35 & $15 \%$ \\
\hline
\end{tabular}

According to the performance test results, the power output is depended on the wind speed condition. Power coefficient of theoretical result is 0.45 and performance test result is 0.35 . It is observed that the power coefficient of theoretical results are higher than the performance test result because of the generator type, drive train losses and wind speed is fluctuated during the test. In the wind power generation system, selection of appropriate generator size and power transmission system is also very important.

\section{CONCLUSION}

From the calculated result of loopwing horizontal axis wind turbine, power output is generated $126 \mathrm{~W}$ at design wind speed of $6 \mathrm{~m} / \mathrm{s}$. In the experiment test condition, electrical power output is produced about $108 \mathrm{~W}$ at rated wind speed $6 \mathrm{~m} / \mathrm{s}$. When the theoretical result and experiment test result are compared, the power output of theoretical result is higher than the experiment test result because the torque is produced by the blades just enough to the startup torque of the simple type generator. The high rpm cannot be got this type of loopwing horizontal axis wind turbine therefore it should be used the low speed and high voltage permanent magnet generator type. If it is used the low speed type permanent magnet generator, the more power can be produced. 


\section{ACKNOWLEDMENT}

The author grateful acknowledge to Dr. Ei Ei Htwe, Pro-Rector, Mandalay Technology University, for her guidance and advice. The author grateful acknowledges Dr. Win Pa Pa Myo, Professor and Head, Department of Mechanical Engineering, Mandalay Technological University, for her permission and guidance to submit the paper. The author would like to express grateful thanks Dr. Myat Myat Soe, Professor, Dr. War War Min Swe, Associate Professor, Dr. Aung Myat Thu, Professor, Department of Mechanical Engineering, Mandalay Technological University, for their great suggestions and encouragement to do this research work. The author would like to special thanks to her parents and her families members for their guidance from childhood till now.

\section{NOMENCLATURES}

$\begin{array}{ll}\mathrm{A}_{1} & \text {-Swept Area }\left(\mathrm{m}^{2}\right) \\ \mathrm{D} & \text {-Diameter of Rotor (m) } \\ \mathrm{C}_{\mathrm{P}} & \text { - Coefficient of Performance } \\ \mathrm{C} & \text {-Chord Length (m) } \\ \mathrm{C}_{\mathrm{D}} & \text {-Drag Coefficient } \\ \mathrm{C}_{\mathrm{L}} & \text {-Lift Coefficient } \\ \mathrm{dF}_{\mathrm{D}} & \text {-Drag Force (N) } \\ \mathrm{dF}_{\mathrm{L}} & \text {-Lift Force (N) } \\ \mathrm{dF}_{\mathrm{T}} & \text {-Thrust Force (N) } \\ \mathrm{dT} & \text {-Torque (Nm) } \\ \mathrm{V}_{\mathrm{r}} & \text {-Relative Velocity (m/s) } \\ \mathrm{dr} & \text {-The Length of Blade Divided Section (m) } \\ \mathrm{r} & \text {-Distance from the Root of the Blade (m) } \\ \varnothing & \text {-Flow Angle (degree) } \\ \omega & \text {-Angular Velocity (rad/s) } \\ \lambda & \text {-Tip Speed Ratio } \\ \alpha & \text {-Angle of Attack (degree) } \\ \beta & \text {-Twist Angle (degree) } \\ \rho & \left.\text {-Fluid Density (kg/m }{ }^{3}\right) \\ \mathrm{P} & \text {-Power (W) } \\ \mathrm{N} & \text {-Rotational Speed (rpm) } \\ \mathrm{n} & \text {-No of Blade } \\ \mathrm{M}_{\mathrm{t}} & \text {-Torsional Moment (Nm) } \\ \mathrm{M}_{\mathrm{b}} & \text {-Bending Moment (Nm) } \\ \mathrm{T}_{\mathrm{e}} & \text {-Equivalent Twisting Moment (Nm) } \\ \mathrm{K}_{\mathrm{b}} & \text {-Bending Moment Factor } \\ \mathrm{K}_{\mathrm{t}} & \text {-Torsional Moment Factor } \\ \mathrm{LWHAWT} & \text {-Loopwing Horizontal Axis Wind Turbine } \\ \eta_{\mathrm{g}} & \text { - Generator Efficiency (\%) } \\ & \end{array}$

\section{REFERENCES}

1. Youngwon Kim, "Profile Design of Loop-Type Blade for Small Wind Turbine" International Journal of Precision Engineering and Manufacturing Green Technology, 2017, Volume. 4, No.4, pp.387-392.

2. Hajime, M., "Influence of Blade Rigidity in Power Characteristicsof Ribbon Type Wind Turbines," Wind Energy UtilizationSymposium, 2014, Volume. 36, pp. 452-455.

3. Park, Y. J., Pan, R., Borror, C. M., Montgomery, D.C., and Lee, G. B., "Erratum to: Simultaneous Improvement of Energy Efficiency and Product Quality in PCB Lamination Process,” Int. J. Precis. Eng. Manuf.-Green Tech. , 2014, Volume. 1, No. 4, pp 353-353.

4. William, D. L.: Impact of Ambient Turbulence on Performance of a Small Wind Turbine, Renewable Energy, 2014, PP 69-73.

5. Ahmed, Siraj Ahmed, Wind Energy Theory and Practice, (2013). 
6. Cemil YIGIT, Ufuk DURMAZ, "Wind Turbine Hajime, M. and Shoichi, T., "An Experimental Study on Power Characteristics of Ribbon Type Wind Turbines," Wind Energy Utilization Symposium, 2012, Volume. 34, pp 292-295.

7. Rajesh Gopinath, Sangsun Kim, Jae-Hong Hahn, Prasad No. Enjeti, Mark B. Yeary and Jo W. Howze, "Development of a Low Cost Fuel Cell Inverter System with DSP Control”, IEEE Transaction on Power Electronic, ,Sept. 2004. Volume 19, No. 5, pp.654-854.

8. Stanley R. Bull, "Renewable Energy Today and Tomorrow", Proceedings of the IEEE, August 2001, Volume. 89, no. 8, pp. 316-381.

9. RiadChedid\&SafurRahman, "Unit Sizing and Control of Hybrid Wind Solar Power Systems", IEEE Transaction of Energy Con version, March 1997, Volume. 12, No. 1, pp. 181-195.

10. Rajesh Gopinath, Sangsun Kim, Jae-Hong Hahn, Prasad No. Enjeti, Mark B. Yeary and Jo W. Howze, "Development of a Low Cost Fuel Cell Inverter System with DSP Control”, IEEE Transaction on Power Electronic, Sept. 2004, Volume 19, No. 5,pp.654-854. 